Revista IBERC
v. 2, n. 2, p. 01-21, mai.-ago./2019
www.responsabilidadecivil.org

\title{
PUBLICIDADE ILÍCITA E INFLUENCIADORES DIGITAIS: NOVAS TENDÊNCIAS DA RESPONSABILIDADE CIVIL
}

\author{
ILLICIT ADVERTISING AND DIGITAL INFLUENCERS:
}

NEW TRENDS OF TORT LAW

\author{
Caio César do Nascimento Barbosa ${ }^{1}$ \\ Michael César Silva ${ }^{2}$ \\ Priscila Ladeira Alves de Brito ${ }^{3}$
}

RESUMO: A pesquisa tem por objetivo analisar a temática da responsabilidade civil dos chamados "influenciadores digitais", sob o prisma da publicidade ilícita, conforme previsão legal no Código de Defesa do Consumidor. Neste estudo, buscou-se analisar a ascensão de tais agentes na relação jurídica de consumo e as inovações publicitárias no âmbito tecnológico que possibilitam as ocorrências da publicidade enganosa ou abusiva, que geram um dever de cuidado pautado nos preceitos ético-jurídicos da boa-fé objetiva, e garantem o equilíbrio na relação de consumo e, consequentemente, maior segurança ao consumidor. No tocante ao tipo de investigação foi escolhido, na classificação Witker (1985) e Gustin (2010), o tipo jurídico-projetivo. De acordo com a técnica da análise de conteúdo, afirma-se que se trata de uma pesquisa teórica, o que se mostrou possível a partir da análise de conteúdo da doutrina, jurisprudência e legislação

\begin{abstract}
The objective of this research was to analyze the issue of tort law of the so-called "digital influencers", under the prism of illicit advertising, as foreseen in the Code of Consumer Protection. This paper seeks to analyze the rise of such agents in the consumer area and technological innovations in advertising that allow the occurrence of misleading or abusive advertising, conceiving a duty of care based on the ethical and legal precepts of objective good faith, ensuring balance in the consumer relationship and, consequently, greater consumer safety. Regarding the type of investigation, in the classification Witker (1985) and Gustin (2010), the legal-projective type was chosen. According to the technique of content analysis, it is said that this is a theoretical research, which has proved possible from the content analysis of doctrine, jurisprudence and relevant legislation. The attribution of objective civil liability to digital influencers has been determined, since, by agreeing to link their image
\end{abstract}

1 Graduando em Direito pela Escola Superior Dom Helder Câmara (curso Direito Integral). ORCID $\mathrm{n}$. 0000000233307717.

2 Doutor e Mestre em Direito Privado pela Pontifícia Universidade Católica de Minas Gerais. Especialista em Direito de Empresa pela Pontifícia Universidade Católica de Minas Gerais. Professor da Pós-graduação Lato Sensu da Pontifícia Universidade Católica de Minas Gerais. Professor da Escola Superior Dom Helder Câmara. Membro do Instituto Brasileiro de Estudos de Responsabilidade Civil (IBERC). Advogado. ORCID n. 0000-00021142-4672.

${ }^{3}$ Mestre em Direito e Instituições Políticas pela Universidade FUMEC. Professora da Escola Superior Dom Helder Câmara. Advogada. ORCID n. 0000000212383294.

Revista IBERC, Minas Gerais, v. 2, n. 2, p. 01-21, mai.-ago./2019 


\section{Revista IBERC}

v. 2, n. 2, p. 01-21, mai.-ago./2019

www.responsabilidadecivil.org

pertinente. Restou determinada a imputação de responsabilidade civil objetiva aos influenciadores digitais, vez que, ao aceitarem vincular sua imagem e fama, em sua plataforma digital, à determinado produto ou serviço, devem buscar todas as diligências necessárias e ampliar seu dever de cuidado e informação para que a publicidade seja lícita, possuindo em mente que podem responder por eventuais danos que venham causar ao consumidor no ambiente digital.

Palavras-chave: Publicidade ilícita. Tecnologia. Responsabilidade civil. Consumidor. Influenciador digital. and fame in their digital platform, to a particular product or service, they should seek all necessary steps and increase their duty of care and information so that advertising be lawful, bearing in mind that they may be liable for any damages they may cause to the consumer in the digital environment.
Keywords: Illicit advertising. Technology. Liability. Consumer. Digital influencer.

SUMÁRIO: 1. Considerações Iniciais. 2. A sociedade de risco e a sociedade do hiperconsumo. 3. Publicidade ilícita no âmbito digital. 4. Digital influencers e a sociedade hiperconectada. 5. Inovações publicitárias e o direito do consumidor. 6. A reparação de danos pelos influenciadores digitais. 7. Considerações finais. 8. Referências.

\section{CONSIDERAÇÕES INICIAIS}

A sociedade contemporânea apresenta aos seus cidadãos inúmeros benefícios ao estilo de vida. O alcance mundial da internet, talvez o maior avanço desse século, possibilitou conexões outrora vistas como inimagináveis. Com tais progressos, a publicidade ganhou espaço maior dentro do mercado de consumo.

Com as plataformas digitais - como as mídias sociais - que atingem e conectam milhões de pessoas, os fornecedores encontraram um instrumento mais eficiente para a divulgação de seus produtos e serviços, de modo a proporcionar ao consumidor uma maior variedade de escolha. Nesse âmbito, ocorrem inúmeros casos de ofensas à legislação consumerista no Brasil, impondo-se a necessidade de lançar luzes sobre a temática.

Discute-se, já há algum tempo na jurisprudência brasileira, a imputação de responsabilidade civil das celebridades no tocante a publicidade ilícita nas quais participam. Ante as inovações da era digital, surge figura similar às celebridades, os chamados influenciadores digitais (digital influencers), indivíduos que via de regra saíram do anonimato e por meio de determinados atributos, tais como, carisma, criatividade e credibilidade, em áreas especificas, conquistaram milhares de seguidores em redes sociais, tornando-se, pelas novas gerações, modelos a serem seguidos.

Tal influência chamou a atenção dos fornecedores, de modo a tornar os influenciadores digitais os novos atores publicitários dessa década. Neste viés, relevante é a análise da possibilidade de imputação de responsabilidade desses sujeitos na sociedade hiperconectada, buscando-se a evitar eventuais danos aos consumidores no mercado de consumo. 


\section{Revista IBERC}

v. 2, n. 2, p. 01-21, mai.-ago./2019

www.responsabilidadecivil.org

Nesse contexto, a publicidade ilícita, no meio digital, possui como peculiaridade uma maior amplitude de propagação e velocidade na divulgação de seus produtos e serviços, impondo-se, por conseguinte, patente assimetria de informações ao consumidor na relação jurídica de consumo.

A relevância da análise demonstra-se como fundamental, vez que os influenciadores digitais assumem cada vez mais espaço nas plataformas digitais, e com isso, conseguem maior abrangência no cenário publicitário, tornando-se, assim, responsáveis pelas publicações que realizam nas mídias sociais. Ainda assim, considerando a eventual imputação de responsabilidade, indaga-se, qual sua modalidade e se existirá ou não a atribuição de solidariedade para com os fornecedores pela divulgação de publicidade ilícita?

O estudo que se propõe desenvolveu-se pela vertente metodológica jurídico-sociológica. No que se refere ao tipo de investigação, foi escolhido, na classificação Witker ${ }^{4}$ e Gustin ${ }^{5}$, o tipo jurídicoprojetivo. De acordo com a técnica de análise de conteúdo, afirma-se que se trata de um artigo teórico, viabilizada a partir da análise de conteúdo doutrinário, normativo e demais dados colhidos na pesquisa.

Por fim, o artigo busca analisar a referida temática e lançar luzes sobre a atuação dos influenciadores digitais no âmbito da publicidade de que participam e a consequente imputação de responsabilidade civil pela difusão de publicidade ilícita no mercado de consumo.

\section{A SOCIEDADE DE RISCO E A SOCIEDADE DO HIPERCONSUMO}

Em função do advento das revoluções tecnológicas e informacionais, o hodierno corpo social pode ser traduzido em duas acepções: a sociedade de risco e a sociedade do hiperconsumo. A primeira, termo cunhado pelo sociólogo alemão Ulrich Beck ${ }^{6}$, traduz-se como uma forma de enxergar o corpo social vivendo sob uma pessimista visão dos riscos, caracterizando uma "cultura do medo". Por esta perspectiva, os riscos apresentam chances de perda, mas, também, chances de êxito: ora podem ser encarados como aspecto negativo, ora como positivo, mas fato é que estão presentes em termos globais neste século, sendo encarados não mais como forças naturais ou atos divinos, mas algo criado pela atividade humana sob a justificativa de benefícios sociais à coletividade. ${ }^{7}$

Conforme preceitua Teresa Ancona Lopez "por mais medidas que sejam tomadas, o risco zero não existe. Em suma, a única certeza na sociedade é a incerteza, pois os riscos não podem ser

\footnotetext{
${ }^{4}$ WITKER, Jorge. Como elaborar una tesis en derecho: pautas metodológicas y técnicas para el estudiante o investigador del derecho. Madrid: Civitas, 1985.

${ }^{5}$ GUSTIN, Miracy Barbosa de Sousa; DIAS, Maria Tereza Fonseca. (Re)pensando a pesquisa jurídica: teoria e prática. 3. ed. Belo Horizonte: Del Rey, 2010.

BECK, Ulrich. Sociedade de Risco: rumo a uma outra modernidade. São Paulo: Editora 34, 2010.

${ }^{7}$ CATALAN, Marcos. A morte da culpa na responsabilidade contratual. São Paulo: Revista dos Tribunais, 2013.
}

Revista IBERC, Minas Gerais, v. 2, n. 2, p. 01-21, mai.-ago./2019 


\section{Revista IBERC}

v. 2, n. 2, p. 01-21, mai.-ago./2019

www.responsabilidadecivil.org

mensurados" ${ }^{\prime 2}$. Diante de tais riscos, cabe aos causadores dos respectivos danos evitar e mitigá-los, visando ao bem-estar e a segurança social. Nessa perspectiva, Nelson Rosenvald preleciona que "evitar e mitigar um dano se converte em questão central e maior desafio para a responsabilidade civil do século XXI." 9

A sociedade contemporânea, também, pode ser encarada como uma sociedade de hiperconsumo, termo cunhado pelo filósofo francês Gilles Lipovetsky ${ }^{10}$. Atos de consumo provocariam uma dita felicidade paradoxal - encaradas como um aumento na qualidade de vida -, e o desejo seria satisfeito a partir do consumo. O consumo, desenfreado, dá espaço ao novo: encara-se uma obsolescência programada, aonde o "velho" cede espaço às inovações em produtos e serviços. Afinal, "é claro que o novo se desgasta. O novo sempre se desgasta, e normalmente não demora muito"11.

Consumo e riscos, deste modo, estão interligados. Neste giro, conforme preceituam Dirceu Pereira Siqueira e Danilo Henrique Nunes "é uma tendência cada vez mais observável que o Direito passe a acompanhar as sociedades digitais." ${ }^{12}$ Diligências devem ser reforçadas para que os atores deste meio - os fornecedores e as pessoas que vinculam determinado bem à sua imagem - não lesem os consumidores. Por esse ângulo, segundo Nelson Rosenvald, "a eliminação prévia dos riscos de dano encontra o seu principal instrumento na instituição de deveres de comportamento prévios, quase sempre por normas legais ou regulamentares"13. Em mesmo sentido, aponta André Menezes Del Mastro que, "no século XXI, a função preventiva ocupa o lugar principal da responsabilidade civil, sendo resultado da sociedade de risco que exige uma tomada de cautela nas atividades desenvolvidas pelos indivíduos." ${ }^{14}$

Eliminar previamente riscos de danos reflete na função preventiva da responsabilidade civil, que visa a garantir o equilíbrio jurídico esperado. Busca-se, deste modo, a adoção da técnica de risk management, que segundo Anderson Schreiber, "somada a responsabilidade civil, buscaria identificar os pontos de risco em cada estrutura organizacional e eliminá-los antes da produção de danos." ${ }^{15}$

\footnotetext{
${ }^{8}$ LOPEZ, Teresa Ancona. Responsabilidade Civil na Sociedade de Risco. In: LOPEZ, Teresa Ancona; LEMOS, Patrícia Faga Iglecias; RODRIGUES JUNIOR, Otavio Luiz (Coordenadores). Sociedade de risco e Direito privado: desafios normativos, consumeristas e ambientais. São Paulo: Atlas, 2013. p. 5.

${ }^{9}$ ROSENVALD, Nelson. As funções da responsabilidade civil: a reparação e a pena civil. 2. ed. São Paulo: Atlas, 2014. p. 79.

${ }^{10}$ LIPOVETSKY, Gilles. A felicidade paradoxal: ensaio sobre a sociedade do hiperconsumo. São Paulo: Companhia das Letras, 2007.

${ }^{11}$ KING, Stephen. Escuridão total sem estrelas. Tradução de Viviane Diniz. Rio de Janeiro: Objetiva, 2015. p. 70.

${ }^{12}$ SIQUEIRA, Dirceu Pereira; NUNES, Danilo Henrique. Conflitos digitais: cidadania e responsabilidade civil no âmbito das lides cibernéticas. Revista Jurídica da UNI7. Centro Universitário 7 de Setembro, Fortaleza, v. 15, n.2, p. 127-138, jul.-dez., 2018. Trecho da p. 136.

${ }^{13}$ ROSENVALD, Nelson. As funções... p. 80.

${ }^{14}$ DEL MASTRO, André Menezes. A função punitivo-preventiva da responsabilidade civil. Revista da Faculdade de Direito, Universidade de São Paulo, p. 765-817, 2016. Trecho da p. 814.

${ }^{15}$ SCHREIBER, Anderson. Novos paradigmas da responsabilidade civil: da erosão dos filtros da reparação à diluição dos danos. 6. ed. São Paulo: Atlas, 2015. p. 228.
} 


\section{Revista IBERC}

v. 2, n. 2, p. 01-21, mai.-ago./2019

www.responsabilidadecivil.org

Outrossim, cabe uma atenta reflexão acerca dos danos causados pelas figuras publicitárias, além da imprescindível observância aos preceitos ético-jurídicos advindos da boa-fé objetiva, em consonância com os princípios da informação, transparência e confiança, e das funções reparatórias e precaucionais da responsabilidade civil, de modo a garantir uma proteção efetiva ao consumidor.

\section{PUBLICIDADE ILÍCITA NO ÂMBITO DIGITAL}

A comunicação e a informação se expandem progressivamente, sendo a mídia o principal veículo para propagação destas na vida contemporânea. Destarte, é notório que a publicidade possui uma presença marcante e seriamente significativa na atual sociedade. O termo publicidade conceitua-se como a divulgação de informações com escopo na difusão de produtos e serviços - de modo que estes sejam adquiridos - para o público consumidor, sendo o instrumento de aproximação dos produtos/serviços do fornecedor. ${ }^{16}$

Nessa linha de intelecção, o artigo 220 da Constituição Federal de 1988 dispõe que "a manifestação do pensamento, a criação, a expressão e a informação, sob qualquer forma, processo ou veículo não sofrerão qualquer restrição, observado o disposto nesta Constituição". ${ }^{17}$ Nesse mesmo sentido, o Código de Defesa do Consumidor (Lei 8078/1990), preconiza ser fundamental a disponibilização de informação qualificada ao consumidor, de modo a evitar a assimetria informacional entre as partes. Insta frisar que, em seu âmbito de aplicação, a informação no CDC assume um caráter dúplice, qual sejam: o direito de informação do consumidor e o dever de informar imposto ao fornecedor, decorrente da necessária observância da boa-fé objetiva. Ademais, o CDC estabelece, em seu artigo $6^{\circ}$, inciso IV a "a proteção contra a publicidade enganosa e abusiva, métodos comerciais coercitivos ou desleais, bem como contra práticas e cláusulas abusivas ou

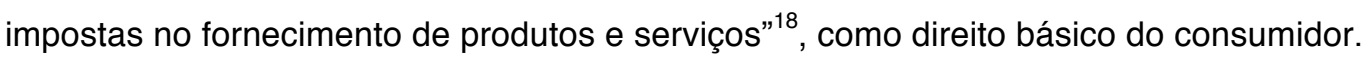

Claudia Lima Marques, em consonância com o disposto, destaca com precisão que "essas normas do CDC aparecem como instrumentos de direito para restabelecer também o equilíbrio, para reestabelecer a força da 'vontade', das expectativas legítimas, do consumidor, compensando, assim, sua vulnerabilidade fática." 19

\footnotetext{
${ }^{16}$ BRAGA NETTO, Felipe Peixoto. Manual de direito do consumidor: à luz da jurisprudência do STJ. 11. ed. Salvador: Juspodivm, 2016.

17 BRASIL. Constituição da República Federativa do Brasil. Disponível em: http://www.planalto.gov.br. Acesso em: 29 jul. 2018.

${ }^{18}$ BRASIL. Código de Defesa do Consumidor (1990). Lei $\mathrm{n}^{\circ}$. 8.078, de 11 de setembro de 1990. Código de Defesa do Consumidor. Disponível em: http://www.planalto.gov.br/ccivil_03/LEIS/L8078.htm. Acesso em: 21 jul. 2018.

${ }^{19}$ BENJAMIN, Antônio Herman V.; MARQUES, Cláudia Lima; BESSA, Leonardo Roscoe. Manual de direito do consumidor. 7. ed. São Paulo: Revista dos Tribunais, 2016. p. 83.
}

Revista IBERC, Minas Gerais, v. 2, n. 2, p. 01-21, mai.-ago./2019 


\section{Revista IBERC}

v. 2, n. 2, p. 01-21, mai.-ago./2019

www.responsabilidadecivil.org

Assim sendo, a Constituição Federal e o Código de Defesa do Consumidor não visam a coibir a publicidade, mas sim evitar danos aos vulneráveis na relação de consumo. Nesse giro, importante destacar que "a inserção da boa-fé objetiva nas relações de consumo trouxe novo impulso à jurisprudência pátria, que passou a utilizá-la como instrumento de proteção ao consumidor e de (re)equilíbrio das relações jurídicas não paritárias."20

Merece atenção a figura do consumidor por equiparação (bystander) prevista no artigo 29 do Código de Defesa do Consumidor. ${ }^{21}$ Este dispositivo possui natureza precaucional, vez que equipara a consumidor qualquer pessoa exposta às práticas comerciais presentes no $C D C$, reivindicando a proteção inerente ao consumidor. Segundo Claudia Lima Marques, tais indivíduos "poderão utilizar as normas especiais do CDC, seus princípios, sua ética de responsabilidade social no mercado, sua nova ordem pública, para combater as práticas comerciais abusivas." 22

Com excelente razão, o Código de Defesa do Consumidor e o Conselho Nacional de Autorregulamentação Publicitária (Conar) proíbem a publicidade considerada ilícita, que se qualifica como a publicidade de cunho enganoso ou abusivo, nos termos do artigo 37 do CDC. ${ }^{23}$

A publicidade enganosa é aquela que induz o consumidor a erro. Dessarte, é transpassada uma ideia de falsidade (parcial ou total) na veiculação de informações, com potencial de lesar o consumidor. Logo, o artigo 37 do CDC veda a atuação comissiva por parte do agente que não oferece as informações corretas, claras e adequadas de que necessita o produto ou serviço. ${ }^{24}$ Portanto, o CDC reprime a divulgação da informação ou comunicação que não seja verdadeira, e, que, por conseguinte, venha a causar prejuízos ao consumidor.

20 SILVA, Michael César. Convergências e assimetrias do princípio da boa-fé objetiva no Direito Contratual contemporâneo. In: BRAGA NETTO, Felipe Peixoto; SILVA, Michael César (Org.). Direito privado e contemporaneidade: desafios e perspectivas do direito privado no século XXI. Belo Horizonte: D'Plácido, 2018, v. 2. p. 125.

21 "Art. 29. Para os fins deste Capítulo e do seguinte, equiparam-se aos consumidores todas as pessoas determináveis ou não, expostas às práticas nele previstas". (BRASIL. Código de Defesa do Consumidor. Lei $\mathrm{n}^{\circ}$. 8.078, de 11 de setembro de 1990. Disponível em: http://www.planalto.gov.br/ccivil_03/LEIS/L8078.htm. Acesso em: 21 jul. 2018).

${ }^{22}$ BENJAMIN, Antônio Herman V.; MARQUES, Cláudia Lima; BESSA, Leonardo Roscoe. Manual... p. 122.

23 "Art. 37. É proibida toda publicidade enganosa ou abusiva.

$\S 1^{\circ}$. É enganosa qualquer modalidade de informação ou comunicação de caráter publicitário, inteira ou parcialmente falsa, ou, por qualquer outro modo, mesmo por omissão, capaz de induzir em erro o consumidor a respeito da natureza, características, qualidade, quantidade, propriedades, origem, preço e quaisquer outros dados sobre produtos e serviços.

$\S 2^{\circ}$. É abusiva, dentre outras a publicidade discriminatória de qualquer natureza, a que incite à violência, explore o medo ou a superstição, se aproveite da deficiência de julgamento e experiência da criança, desrespeita valores ambientais, ou que seja capaz de induzir o consumidor a se comportar de forma prejudicial ou perigosa à sua saúde ou segurança.

$\S 3^{\circ}$. Para os efeitos deste código, a publicidade é enganosa por omissão quando deixar de informar sobre dado essencial do produto ou serviço. (BRASIL. Código de Defesa do Consumidor. Lei $\mathrm{n}^{\circ}$. 8.078, de 11 de setembro de 1990. Disponível em: http://www.planalto.gov.br/ccivil_03/LEIS/L8078.htm. Acesso em: 21 jul. 2018).

${ }^{24}$ Conforme preceitua Marcelo Kokke Gomes a publicidade "deve ser veiculada de forma clara e perceptível, de modo que o consumidor logo perceba do que se trata." (GOMES, Marcelo Kokke. Responsabilidade Civil: dano e defesa do consumidor. Belo Horizonte: Del Rey, 2001. p.142). 


\section{Revista IBERC}

v. 2, n. 2, p. 01-21, mai.-ago./2019

www.responsabilidadecivil.org

Todavia, não se veda apenas a publicidade enganosa comissiva, mas se pune do mesmo modo a atuação omissiva do fornecedor na divulgação de seus produtos/serviços. Logo, se extrai a ideia da supressão de informações que sejam essenciais ao produto ou serviço, vez que o consumidor não possui discernimento de entender as características necessárias que estão sendo omitidas, alterando-se a percepção da autonomia privada do consumidor e, podendo atingir sua integridade psicofísica e causar graves consequências. ${ }^{25}$ Cabe apontar, conforme preceituam Benjamin, Marques e Bessa que "o Código nutre pela publicidade enganosa por omissão a mesma antipatia que manifesta pela publicidade enganosa comissiva." 26

A publicidade abusiva é qualificada pelo Código de Defesa do Consumidor, como a publicidade que ofende valores básicos da sociedade (como os relacionados a moral e a ética), bem como, a que possui caráter discriminatório, incitando a violência, explorando medo ou superstição, ofendendo hipervulneráveis, desrespeitando valores ambientais ou induzindo o consumidor a um comportamento reprovável. Segundo Marques, a referida espécie de publicidade ilícita é "a publicidade antiética, que fere a vulnerabilidade do consumidor, que fere valores sociais básicos, que fere a própria sociedade como um todo." 27

Nesse mesmo sentido, em consonância com o exposto, Lisboa aponta que "é incabível qualquer conduta de tratamento discriminatório aos consumidores, inclusive a respeito da oferta e publicidade de produtos e serviços." ${ }^{28}$

O Código de Defesa do Consumidor proíbe, também, a publicidade clandestina, vez que é disposto em seu artigo 36 que "a publicidade deve ser veiculada de tal forma que o consumidor, fácil e imediatamente, a identifique como tal". ${ }^{29}$ Nessa linha de raciocínio, o princípio da identificação da mensagem publicitária impõe o dever de informar ao consumidor de que o que ele vê ou ouve tratase de uma publicidade. ${ }^{30}$

Benjamin, Marques e Bessa preconizam que a "publicidade que não quer assumir a sua qualidade é atividade que, de uma forma ou de outra, tenta enganar o consumidor. E o engano, mesmo o inocente, é repudiado pelo Código de Defesa do Consumidor." ${ }^{31}$ Nesse giro, é indubitável que os fornecedores e profissionais do marketing possuem o conhecimento de que a publicidade que não parece publicidade apresenta um maior efeito persuasivo ${ }^{32}$, gerando discussões e infortúnios no que tange as celebridades e influenciadores digitais que promovem produtos e serviços de forma

\footnotetext{
${ }^{25}$ BRAGA NETTO, Felipe Peixoto. Manual... 2016.

${ }^{26}$ BENJAMIN, Antônio Herman V.; MARQUES, Cláudia Lima; BESSA, Leonardo Roscoe. Manual... p. 295.

${ }^{27}$ MARQUES, Claudia Lima. Contratos no código de defesa do consumidor: o novo regime das relações contratuais. 7. ed. São Paulo: Revista dos Tribunais, 2014. p. 878.

${ }^{28}$ LISBOA, Roberto Senise. Confiança contratual. São Paulo: Atlas, 2012. p. 172.

${ }^{29}$ Disponível em: http://www.planalto.gov.br/ccivil_03/LEIS/L8078.htm. Acesso em: 21 de jul. 2018.

30 GUIMARÃES, Paulo Jorge Scartezzini. A publicidade ilícita e a responsabilidade civil das celebridades que dela participam. 2. ed. rev., atual, e ampl. São Paulo: Revista dos Tribunais, 2007.

${ }^{31}$ BENJAMIN, Antônio Herman V.; MARQUES, Cláudia Lima; BESSA, Leonardo Roscoe. Manual... p. 288.

${ }^{32}$ GUIMARÃES, Paulo Jorge Scartezzini. A publicidade... 2007.
} 


\section{Revista IBERC}

v. 2, n. 2, p. 01-21, mai.-ago./2019

www.responsabilidadecivil.org

indevida.

Havendo a constatação de publicidade ilícita, impõe-se a imputação de responsabilidade civil objetiva aos fornecedores, vez lhes são impostos deveres pré-contratuais norteados pelos preceitos ético-jurídicos da boa-fé objetiva, em consonância, com os princípios da informação, transparência e confiança. Por essa perspectiva, é apontado por Marques que "fazer veicular uma publicidade caracterizada como abusiva constitui ilícito civil, e o responsável civilmente é aquele fornecedor que se 'utiliza' da publicidade abusiva (ou enganosa) para promover os seus produtos ou seus serviços." ${ }^{33}$

De mesmo modo, é conferida a responsabilidade objetiva às agências de publicidade e, também, às celebridades que vinculam sua imagem à determinado bem - afinal, quem aufere $o$ bônus deve arcar com o ônus -, visto que o CDC impõe ao fornecedor um agir cooperativo e transparente na relação de consumo, prevenindo-se assim eventuais danos aos consumidores.

Consoante o escólio de Guimarães, "se a celebridade não está obrigada a participar da publicidade, caso venha a aceitar o 'trabalho', deverá prestar as informações de forma a não prejudicar terceiros." ${ }^{34}$ Ressalta-se, ainda, que, são impostas ao fornecedor a veracidade das informações, a correção dos desvios publicitários e comunicação que causem prejuízos ao consumidor.

Ademais, é imprescindível a observância na relação jurídica de consumo dos princípios da boa-fé objetiva (preceitos ético-jurídicos de comportamento), da informação (informação necessária e suficiente de todo conteúdo contratual pertinente), da confiança (preservar as legítimas expectativas despertadas) e da transparência (a qualificação da informação fornecida que deve ser clara, correta, ostensiva e adequada). A incidência de tais princípios visa a garantir a futura expectativa do consumidor (padrão ou equiparado), que se encontra em posição de vulnerabilidade (econômica, técnica, e, principalmente, informativa) perante aos anunciantes, fornecedores, celebridades ou influenciadores digitais, notadamente, pela patente assimetria de informação existente na relação de consumo virtual.

Desta forma, é imprescindível que as partes atuem nas relações jurídicas obrigacionais firmadas, com observância aos deveres anexos de conduta, os quais impõem para além da obrigação jurídica principal, deveres fiduciários (obrigação complexa), os quais objetivam resguardar a legítima expectativa e a confiança mútua existente entre as partes. ${ }^{35}$

Alinhando-se as previsões legais inseridas no Código de Defesa do Consumidor, é papel

\footnotetext{
${ }^{33}$ MARQUES, Claudia Lima. Contratos... p. 879.

${ }^{34}$ GUIMARÃES, Paulo Jorge Scartezzini. A publicidade... p.168.

${ }^{35}$ SILVA, Michael César. Convergências e assimetrias do princípio da boa-fé objetiva no Direito Contratual contemporâneo. In: BRAGA NETTO, Felipe Peixoto; SILVA, Michael César (Org.). Direito... p. 121.
} 


\section{Revista IBERC}

v. 2, n. 2, p. 01-21, mai.-ago./2019

www.responsabilidadecivil.org

elementar dos fornecedores atentar aos meios adequados de publicidade que possam atingir seu objetivo principal, qual seja, apresentar e despertar o interesse dos consumidores por determinado produto ou serviço, mas, de modo que, não the sejam causados prejuízos ou ofensas. Por fim, relevante salientar que as novas tecnologias são ferramentas que, se utilizadas corretamente, podem ensejar benefícios para ambos os sujeitos da relação jurídica de consumo, inovando as relações no âmbito consumerista e garantindo segurança jurídica para as partes.

\section{DIGITAL INFLUENCERS E A SOCIEDADE HIPERCONECTADA}

A sociedade contemporânea progressivamente apresenta inúmeros avanços na área da tecnologia, ocasionando inúmeros benefícios para o estilo de vida do cidadão. Dentro desse contexto, as mídias sociais e a difusão da internet, se tornam cenários para uma sociedade hiperconectada, que possibilitam o acesso à informação e promovem a comunicação de forma instantânea, provandose verdadeiros e efetivos os avanços deste século. Neste cenário, surge um fenômeno impossível de se ignorar, a presença dos influenciadores digitais, no contexto das relações jurídicas de consumo virtuais.

Segundo Almeida, et al., "influenciadores digitais são formadores de opinião virtuais que representam uma alternativa para empresas que confiam na comunidade reunida em torno desses perfis como público-alvo de divulgação." 36

Os digital influencers são indivíduos que exercem demasiada influência sobre um determinado público, possuindo a habilidade de criar e influenciar a mudança de opiniões e comportamentos, podendo conceber padrões por meio de diálogos diretos com seus seguidores. Sendo por muitas vezes criadores de conteúdo, por meio das mídias sociais, em especial, nas plataformas do Instagram e do Youtube, com conteúdo muitas vezes exclusivos, geram uma conexão com seu público em diversas áreas de atuação, como cultura e entretenimento, moda, cuidados com a saúde e corpo, gastronomia, dentre outros.

Acerca da diferenciação dos influenciadores digitais com as celebridades, aponta Karhawi que:

[...] enquanto uma celebridade está distante, sob holofotes, traçando um caminho de sucesso que parece muito distante de quem os assiste no cinema ou na televisão, os influenciadores digitais estão no Facebook, no Instagram, no Snapchat, em

\footnotetext{
${ }^{36}$ ALMEIDA, Marcos Inácio Severo de, et al. Quem Lidera sua Opinião? Influência dos Formadores de Opinião Digitais no Engajamento. Revista de Administração Contemporânea. Rio de Janeiro: ANPAD, 2018, v. 22, n. 1, p. 16.
} 


\section{Revista IBERC}

v. 2, n. 2, p. 01-21, mai.-ago./2019

www.responsabilidadecivil.org

espaços ocupados por 'pessoas comuns' com quem dialogam em igualdade. ${ }^{37}$

Ainda assim, alguns influenciadores acabam se tornando celebridades, mas isso ocorre de modo externo à sua função original, ou seja, ganham fama por seu número de seguidores e indubitável influência e passam a seguir outras áreas, como atuar em programas de televisão, por exemplo; nestes casos, cabe dizer, o indivíduo deverá ter seu papel como digital influencer e como celebridade analisados de forma distinta, vez que o público atingido não será necessariamente o mesmo.

A identificação do consumidor com o digital influencer é formada justamente pelo fato deste último ser considerado uma pessoa normal, que se conecta com muitas outras por meio das plataformas digitais, se relacionando em áreas de que têm conhecimento. Formadores de opiniões, os influenciadores não apresentam ou representam personagens, mas sim eles mesmos em seu cotidiano, tornando sua aproximação com seus seguidores mais acessível e descomplicada.

Essa conexão com o público de forma descontraída se tornou um grande atrativo para os fornecedores. Isto acontece, pois, o consumidor em potencial possui uma relativa proximidade - e confiança - com o digital influencer, no qual muitas vezes se espelha, preferindo a credibilidade do influenciador a de uma marca ou outra pessoa com a qual nunca teve contato. $\mathrm{O}$ consumidor se sente mais à vontade com a publicidade feita pelo indivíduo que Ihe transmite confiança - na qual existe previamente uma relação de contato, vez que ele acompanha diariamente tal indivíduo em seu feed ${ }^{38}$ nas redes sociais -, pois não chega a ser um contato aparentemente artificial, e sim descontraído, diferente dos inúmeros spams existentes na internet. Além disso, a grande maioria dos consumidores se encontra conectado na internet nessa década, tornando a proximidade e o acesso aos produtos e serviço simples e facilitado.

Logo, em uma época na qual o corpo social se encontra conectado e o acesso à informações, produtos e serviços é mais simples que outrora, deve-se ponderar acerca da responsabilidade civil dessas pessoas que possuem enorme poder de influência, no tocante a divulgação e propagação de publicidade ilícita.

Nessa linha de raciocínio, estes influenciadores - agentes de destaque na era da publicidade acoplada à tecnologia - devem tomam as diligências necessárias, de forma a garantir a integridade do consumidor, sob pena de imputação de responsabilidade civil, ou apesar de vincularem sua imagem e fama por determinada quantia de dinheiro ou percepção de bens/serviços

\footnotetext{
${ }^{37}$ KARHAWI, Issaaf. Influenciadores digitais: o Eu como mercadoria. In: SAAD, Elizabeth Corrêa; SILVEIRA, Stefanie Carlan. (organizadores). Tendências em comunicação digital. São Paulo: ECA/USP, 2016. p. 46.

${ }^{38} \mathrm{O}$ feed qualifica-se como "recurso para notificar o usuário de um blog ou outro site atualizado com frequência de que novo conteúdo foi adicionado." (OXFORD. English Living Dictionaries. Disponível em: https://en.oxforddictionaries.com/definition/feed. Acesso em: 17 out. 2018, tradução nossa).

No original: "A facility for notifying the user of a blog or other frequently updated website that new content has been added".
} 


\section{Revista IBERC}

v. 2, n. 2, p. 01-21, mai.-ago./2019

www.responsabilidadecivil.org

dos fornecedores, não possuem responsabilidade para com suas publicações de viés publicitário no ambiente virtual?

Busca-se, assim, por meio da análise de sua atuação no mercado de consumo, responder a tais questionamentos nos próximos tópicos a serem aqui abordados.

\section{INOVAÇÕES PUBLICITÁRIAS E O DIREITO DO CONSUMIDOR}

Os influenciadores digitais, em sua posição de novos atores da sociedade digital e do hiperconsumo, são criadores de conteúdo, o que lhes garante ampla liberdade nas plataformas digitais. Neste sentido, os fornecedores permitem que tais criadores de conteúdo promovam produtos e serviços pela forma que Ihes convier, de modo a tornar a publicidade natural - com um caráter persuasivo -, e não algo artificial.

Segundo Guimarães, "a celebridade, para responder pelos danos causados em decorrência de sua informação, deve ter um benefício, seja ele qual for." ${ }^{39}$ Geralmente se recebe uma remuneração pecuniária - como é o usual em tais relações -, mas fenômeno comum no ramo dos digitais influencers são os populares "mimos e recebidos". Os fornecedores proporcionam produtos/serviços para estas pessoas de forma gratuita, com o intuito de se obter uma troca, qual seja, a publicidade nas plataformas digitais.

O modelo padrão de publicidade veiculada pelos digitais influencers é simples. O anunciante produz um pequeno resumo das características e informações do produto ou serviço (briefing) e o repassa para o influenciador digital, que lhe divulgará nas mídias sociais. A divulgação geralmente ocorre por meio de fotos no feed e por Stories (vídeos de no máximo 15 segundos que desaparecem em 24 horas) no caso do Instagram, e por meio de vídeos na plataforma do Youtube. Tais plataformas são as mais utilizadas, atualmente, ainda que existam divulgações em mídias sociais como o Facebook, Snapchat ou Twitter.

Com base no briefing, o fornecedor pode the ditar algo a ser repassado aos potenciais consumidores ou the dar autonomia para que se crie algo despojado. O usual é que fique explícito de que a publicação se trata de um merchandising, por meio de hashtags em indicações textuais ou mesmo na própria publicação, indicando que se trata de uma publicidade paga, em consonância com os ditames do artigo 36 do CDC. Nessas condições, existindo o dever de cuidado na veiculação do produto/serviço, a publicidade é lícita. Todavia, caso a publicidade desrespeite os preceitos norteadores da boa-fé objetiva, da informação, transparência e confiança ou os valores sociais, morais, dentre outros - referentes ao artigo 37 do CDC -, será considerada ilícita e ensejará a

\footnotetext{
${ }^{39}$ GUIMARÃES, Paulo Jorge Scartezzini. A publicidade... p. 174.
}

Revista IBERC, Minas Gerais, v. 2, n. 2, p. 01-21, mai.-ago./2019 


\section{Revista IBERC}

v. 2, n. 2, p. 01-21, mai.-ago./2019

www.responsabilidadecivil.org

responsabilização do fornecedor, pelos eventuais danos causados aos consumidores.

Porém, tal modelo não é seguido diversas vezes, ocorrendo violação do princípio da identificação da mensagem publicitária, de forma a se desrespeitar o artigo 36 do CDC. 0 merchandising, por exemplo, atua nesse viés. Mais comum em vídeos no Youtube, no qual determinado produto ou serviço aparece ou é mencionado (de forma implícita), em regra não geraria vinculação, tampouco, responsabilidade, desde que, aclarado fosse ao consumidor que se trataria de uma publicidade, o que se reitera não acontece na maioria dos casos: a publicidade é veiculada de maneira quase despercebida (clandestina), de forma a incitar a curiosidade do consumidor.

Nessa linha de raciocínio, a identificação da publicidade apresentada é fundamental, vez que, conforme explicam Simas e Souza Júnior, "ao deixar claro que se trata de uma publicidade o consumidor pode ter melhores condições de ponderar sobre as suas escolhas." ${ }^{40}$

O puffing, também, se faz presente entre as publicidades do meio digital, mas dificilmente gera responsabilidade civil. Trata-se de um exagero na publicidade, que a amplia por meio de hipérboles para gerar um maior alcance. O puffing apenas vincula se for objetivo. Se for subjetivo, nada haveria vinculação. Importante dizer que se a publicidade for falsa, ensejará responsabilidade do fornecedor ${ }^{41}$. Benjamin, Marques e Bessa preceituam que "o exagero, mostrando-se capaz de induzir o consumidor em erro ou abusando de valores sociais, presta-se à caracterização da publicidade enganosa e abusiva." ${ }^{42}$

Ressalta-se, porém, que novos meios de promoção de bens/serviços surgem de modo constante no âmbito digital. Uma inovação publicitária muito utilizada na prática são os chamados reviews (ou resenhas). O review consiste em expor ao espectador as funções, qualidades e defeitos (em relação aos defeitos e vícios, atuam em vídeos com caráter informacional, e não publicitário) de produtos e serviços adquiridos, com o intuito de informar tais características mencionadas ao consumidor por meio de vídeos, ocasionalmente, podendo acontecer por meio de posts "publicação (algo escrito, imagem ou outro item de conteúdo) on-line, normalmente em um blog, um site ou um aplicativo de mídia social” ${ }^{43}$. Pode ocorrer por iniciativa do próprio influenciador - hipótese essa que não ensejaria a vinculação -, ou pela iniciativa do fornecedor (que pode remunerar em pecúnia ou pelo objeto), existindo uma publicidade mais econômica, e por muitas vezes, parcial, não expondo o bem como realmente é, mas de forma artificial, obrigando-se à avaliar o produto ou serviço de forma inteiramente positiva, mesmo que não o seja realmente.

\footnotetext{
${ }^{40}$ SIMAS, Danielle Costa de Souza; SOUZA JÚNIOR, Albefredo Melo de. Sociedade em rede: os influencers digitais e a publicidade oculta nas redes sociais. Revista de Direito, Governança e Novas Tecnologias. Salvador, V. 4, n. 1, p. 17-32, jan-jun. 2018. Trecho da p. 27.

${ }^{41}$ GUIMARÃES, Paulo Jorge Scartezzini. A publicidade..., 2007.

${ }^{42}$ BENJAMIN, Antônio Herman V.; MARQUES, Cláudia Lima; BESSA, Leonardo Roscoe. Manual... p. 294.

${ }^{43}$ No original: Publish (a piece of writing, image, or other item of content) online, typically on a blog or social media website or application. (OXFORD. English Living Dictionaries. Disponível em: https://en.oxforddictionaries.com/definition/feed. Acesso em: 17 out. 2018).
} 


\section{Revista IBERC}

v. 2, n. 2, p. 01-21, mai.-ago./2019

www.responsabilidadecivil.org

Outra inovação - que por muitas vezes une-se à prática dos reviews e dos ditos "mimos" - é o popular fenômeno do unboxing, que se traduz em uma transmissão virtual em que se desempacotam novos produtos, despertando no espectador uma sensação prazerosa de se "abrir" um novo bem material. A priori, caracterizava-se como algo positivo, no qual o consumidor era exposto ao ato do desempacotamento como a verdade nua e crua do bem, expondo suas qualidades ou seus defeitos. ${ }^{44}$ Diferencia-se do review por ser algo "em tempo real", ou seja, não ocorreria uma avaliação prévia do bem, consistindo na prática de avaliar o produto sem uma maior profundidade. Assim como o review, tal prática tornou-se barata aos fornecedores, sendo vantajoso para estes em termos de custo-benefício, para fins de se atingir determinados públicos-alvo.

O maior problema quando se aborda a temática dos influenciadores digitais relacionando-os a publicidade se apresenta na seguinte questão: como saber se o influenciador está divulgando um produto ou serviço ou dando uma opinião pessoal descompromissada?

Não são raras as hipóteses nas quais as pessoas publicam fotos ou vídeos com representações do produto ou serviço, descrevendo suas qualidades e não deixando clara a intenção de sua publicação: para o seu público, pode parecer ser uma opinião descompromissada - no sentido da pessoa que publicou ser apenas um mero consumidor que comprou o produto ou adquiriu o serviço e aprovou o mesmo, de forma natural, como a indicação de uma pessoa amiga -, mesmo que seja hipótese da publicidade clandestina, vez que a mensagem é transmitida de modo amistoso e não agressivo.

Neste giro, destaca-se, por oportuno, a Representação $n^{\circ}$ 211/15 do Conselho Nacional de Autorregulamentação Publicitária. ${ }^{45} \mathrm{~A}$ referida representação surgiu após reclamação de consumidores acerca de postagem na plataforma do Instagram pela influenciadora digital Gabriela Pugliesi, em que a mesma supostamente divulgava produto da marca Skol sem a clara identificação de publicidade. Ademais, apontava-se o potencial de indução ao consumo de bebidas alcóolicas à menores de idade. A Companhia de Bebidas das Américas (AMBEV), alegou que a publicação surgiu por iniciativa da blogueira, que por sua vez, não se manifestou acerca das reclamações. $A$ ausência de manifestação fez com que o relator (com voto acolhido pela maioria) considerasse tais denúncias como verídicas, de modo a considerar tais postagens como publicidade ainda que velada, recomendando-se alteração do post e advertindo-a.

Contudo, o "friendly advice" (opinião amiga, descompromissada) existe no âmbito digital. São os casos em que realmente não ocorre publicidade, mas conselhos por parte da personalidade, que publica sobre determinado produto ou serviço como um amigo recomendaria.

44 KERSCHENSTEINER, Klaus. UNBOXING: RELEVANT TO MEDIA LINGUISTICS? Disponível em: http://10plus1journal.com/wpcontent/uploads/2015/09/06_MIN_TALK_Kerschensteiner1.pdf. Acesso em: 29 jul. 2018.

${ }^{45}$ CONAR (Conselho Nacional de Autorregulamentação Publicitária). Representação $n^{\circ}$ 211/15. Julg. Fev. 2016. Disponível em http://www.conar.org.br/processos/detcaso.php?id=4259. Acesso em: 26 jul. 2018.

Revista IBERC, Minas Gerais, v. 2, n. 2, p. 01-21, mai.-ago./2019 


\section{Revista IBERC}

v. 2, n. 2, p. 01-21, mai.-ago./2019

www.responsabilidadecivil.org

Atenção é merecida nestes casos, pois distingui-los da publicidade velada não se mostra tarefa fácil, como bem sabem os fornecedores, que se utilizam de tal lacuna para impulsionar anúncios por intermédio dos influenciadores. Como bem aponta Franco, "os influenciadores ao realizarem publicidade como se fosse uma 'dica de amigo' induzem o seguidor a uma compra que não é realizada de forma consciente."46 O CONAR, como bem fez na referida representação, deve analisar de forma atenta as manifestações que possam ser identificadas ao consumidor como publicidade, de modo a não ser lesiva para o consumidor, garantindo a este uma maior segurança no mercado de consumo.

Muitos influenciadores digitais, agindo em conformidade com os preceitos ético-jurídicos da boa-fé objetiva, deixam explícito, de modo que o consumidor facilmente identifique, que a divulgação se trata de veiculação de publicidade, e este deve ser o caminho a ser seguido de forma universal por todos que utilizam de suas plataformas digitais para promover de forma adequada produtos ou serviços. Afinal, com lastro nos apontamentos de Siqueira e de Nunes "a concepção de que a internet é uma 'terra de ninguém' não tão somente é ultrapassada, como também é equivocada." 47

Todavia, com as inovações no âmbito digital outrora mencionadas, torna-se árduo o trabalho de filtrar o que seria publicidade ilícita ou opinião descompromissada. Urge a necessidade de uma atuação do Poder Público no sentido de analisar e coibir eventuais excessos na publicidade realizada pelos influenciadores para deixar claro ao destinatário de seu conteúdo a real intenção de suas publicações, para fins de se evitar a ocorrência de publicidades ilícitas no meio digital, impondose responsabilidade civil pela ocorrência de danos a terceiros (consumidores), desestimulando os influenciadores a reincidirem em tal comportamento lesivo.

\section{A REPARAÇÃO DE DANOS PELOS INFLUENCIADORES DIGITAIS}

Ante à conjuntura previamente exposta, é possível indagar-se a real necessidade de se responsabilizar o influenciador digital nas ocorrências de publicidade ilícita. Na sociedade de risco, todas as pessoas que se comprometam a veicular sua imagem ou influência à um bem devem estar cientes de seus riscos, tendo consciência de que sua conduta pode gerar atos ilícitos que ensejam reparação. Dessarte, o influenciador não é obrigado a veicular tais atributos, mas caso aceite, deve

\footnotetext{
${ }^{46}$ FRANCO, Denise Sirimarco. A publicidade no Instagram feita por digital influencers à luz da boa-fé objetiva e do dever de informação. 2016. Dissertação Curso de Pós-Graduação Lato Sensu da Escola de Magistratura do Estado do Rio de Janeiro, Rio de Janeiro. p. 10. Disponível em: http://www.emerj.tjri.jus.br/paginas/trabalhos_conclusao/2semestre2016/pdf/DeniseSirimarcoFranco.pdf. Acesso em: 26 jul. 2018.

${ }^{47}$ SIQUEIRA, Dirceu Pereira; NUNES, Danilo Henrique. Conflitos digitais: cidadania e responsabilidade civil no âmbito das lides cibernéticas. Revista Jurídica da UNI7. Centro Universitário 7 de Setembro, Fortaleza, v. 15, n. 2, jul.-dez., 2018, p. 127-138 (trecho da p. 136).
}

Revista IBERC, Minas Gerais, v. 2, n. 2, p. 01-21, mai.-ago./2019 


\section{Revista IBERC}

v. 2, n. 2, p. 01-21, mai.-ago./2019

www.responsabilidadecivil.org

atentar-se para que sua conduta não lese potenciais consumidores, que se espelham e ficam atentos aos padrões e opiniões afirmados por terceiros.

Ocasionalmente, surgem episódios da publicidade ilícita, sejam pelas inovações publicitárias no ramo digital ou pelos métodos usuais da indústria do marketing. Perante tais fatos em analogia à responsabilidade civil das celebridades -, verifica-se, em relação a responsabilidade dos digital influencers, que "as pessoas que se pretende responsabilizar tiveram proveitos de sua atividade (seja proveito econômico ou outro qualquer), deverão elas assumir os riscos de sua atividade" ${ }^{48}$. Destarte, impõem-se de forma inequívoca a incidência de responsabilidade objetiva dos influenciadores digitais pelas informações (ou a falta delas) veiculadas nas plataformas digitais.

Nessa perspectiva preleciona Paulo Jorge Scartezzinni Guimarães, que as celebridades "devem cumprir seu dever jurídico originário, agindo de forma prudente, colocando acima dos seus interesses econômicos a preocupação em não enganar ou não permitir que se enganem os consumidores." 49

Noutro giro, Dias preconiza que "não faria mesmo sentido imputar às celebridades, quando prestam informações ou recomendações de conteúdo publicitário, responsabilidade objetiva, fundada na teoria do 'risco da atividade', esta sim, aplicável aos fornecedores."

A autora aponta, ainda, que as celebridades "não podem assumir responsabilidade idêntica à do fornecedor, notadamente porque em muitas situações atuam como mero 'porta-voz' do anunciante, sem qualquer declaração com base em suas experiências pessoais de uso dos produtos ou serviços." ${ }^{51}$ Destarte, não seria razoável conferir responsabilidade igual ao do fornecedor se o digital influencer agir como mero representante.

Porém, conforme exposto previamente, muitos influenciadores das plataformas digitais são criadores de conteúdo, assumindo posição de garantidores das informações veiculadas, razão pela qual deve ser conferida a responsabilidade objetiva aos influenciadores que possuem tal liberdade de criação. Em todos os casos, devida é a atenção aos preceitos da boa-fé objetiva, informação, transparência e confiança, que devem sempre estar presentes. Logo, o influenciador deve atentar-se às informações contidas no briefing; caso conheça os riscos dos produtos e serviços, não os omitir, não emprestar sua fama e influência a fornecedores duvidosos, dentre outros.

Nesse contexto, Franco preceitua que:

[...] o influenciador, ao transmitir sua mensagem, deve estar ciente dos deveres a que está sujeito, como dever de informação, nele compreendido o dever de informar

\footnotetext{
48 GUIMARÃES, Paulo Jorge Scartezzini. A publicidade... p. 202.

${ }^{49}$ GUIMARÃES, Paulo Jorge Scartezzini. A publicidade... p. 223.

50 DIAS, Lucia Ancona Lopez de Magalhães. Publicidade e direito. São Paulo: Revista dos Tribunais, 2010. p. 306.

${ }^{51}$ DIAS, Lucia Ancona Lopez de Magalhães. Publicidade... p. 305.
} 


\section{Revista IBERC}

v. 2, n. 2, p. 01-21, mai.-ago./2019

www.responsabilidadecivil.org

corretamente; o dever de lealdade, considerando que o seguidor confia nele; e o dever de solidariedade. ${ }^{52}$

Deste modo, pugna-se pela imputação de responsabilidade do influenciador digital, posto que, não está obrigado a aceitar nenhum trabalho, mas, caso venha a aceitar, deve agir de modo que sejam observados os preceitos ético-jurídicos impostos pela boa-fé objetiva, aceitando os riscos pela publicidade que irá vincular sua imagem, fama ou prestígio, sendo descabido a conceituação de tais indivíduos como profissionais liberais.

Rais e Barbosa apontam que:

Apesar de serem "sujeitos comuns", os influenciadores digitais são verdadeiros profissionais da web e têm, portanto, a obrigação de respeitar os princípios de boafé e transparência em prol dos consumidores, devendo deixar explícita a sua relação comercial com a empresa do produto divulgado. ${ }^{53}$

Por possuírem ampla liberdade de vinculação publicitária, diferentemente das "celebridades convencionais", acredita-se que deve ser reforçado o dever de cuidado dos influenciadores digitais, de modo que o mesmo não banalize a publicidade e inobserve diretrizes básicas, em especial o dever de informação, para anunciar algum produto ou serviço. A aceitação de vincular sua imagem, plataforma e confiança deve ser levada a sério, de modo que o influenciador tenha em mente que poderá responder por eventuais danos causados aos consumidores.

A partir do cenário vislumbrado, Franco salienta que "o fato de o digital influencer informar que está publicitando naquela foto ou vídeo, além de cumprir a lei, evita diversos problemas para o consumidor, pois possibilita que o seguidor adote uma posição defensiva frente a publicidade." ${ }^{54}$

Acerca da possibilidade dos produtos ou serviços serem acometidos posteriormente por vícios ou defeitos, entende-se que o influenciador que o promoveu digitalmente se exime de sua responsabilidade, vez que na hipótese de responsabilidade pelo fato do produto/serviço ou responsabilidade pelo vício do produto/serviço não possuirá relação direta com a publicidade ilícita vinculada, devendo o lesado acionar, exclusivamente, o fornecedor pelos prejuízos causados a sua incolumidade física/psicológica ou econômica.

Oportuno é atentar-se às funções da responsabilidade civil neste século, vez que pouco se discute acerca delas. Fato é que, atualmente, a responsabilidade civil exerce, em grande parte, uma função meramente reparatória. Diante dos avanços na temática, é despiciendo o ordenamento pátrio se reduzir apenas a função reparatória. Isto pois, atenção e urgência são merecidas às funções

\footnotetext{
${ }^{52}$ FRANCO, Denise Sirimarco. A publicidade ... p.15.

${ }^{53}$ RAIS, Diogo; BARBOSA, Nathalia Sartarello. O reflexo da sociedade do hiperconsumo no instagram e a responsabilidade civil dos influenciadores. Revista Direitos Culturais, Santo Ângelo, V. 13, n. 30, p. 73-88, mai.ago. 2018 (trecho da p. 85).

${ }^{54}$ FRANCO, Denise Sirimarco. A publicidade... p.14.
} 


\title{
Revista IBERC
}

v. 2, n. 2, p. 01-21, mai.-ago./2019

www.responsabilidadecivil.org

punitivas e precaucionais. Relacionando-se à publicidade ilícita e os influenciadores digitais que dela participam, é de extrema necessidade a aplicabilidade de tais funções pelo ordenamento jurídico.

Nessa linha de intelecção, o digital influencer - sabendo dos potenciais riscos do produto ou serviço ou omitindo informações ou acrescentando informações enganosas - deve ser sancionado, como forma de desestímulo, de forma a prevenir novas condutas que atentem a este meio. A função precaucional, por sua vez, possui papel crucial nesta tríade, devendo o influenciador atentar-se aos preceitos oriundos da boa-fé objetiva, informação, transparência e confiança, com a finalidade de se evitar possíveis danos. Neste viés, Braga Netto aponta com precisão que:

O direito do século XXI não se satisfaz apenas com a reparação dos danos. Mais importante do que tentar reparar - sempre imperfeitamente, como se sabe - os danos sofridos, a tutela mais adequada, e mais conforme à Constituição, é a tutela preventiva, que busca evitar que os danos ocorram ou que continuem a ocorrer. A função preventiva assume, portanto, neste século, fundamental importância. ${ }^{55}$

Alinhado à tais funções, no tocante a responsabilidade civil das personalidades - sejam celebridades ou influenciadores digitais - relacionada à publicidade ilícita, preceitua Rosenvald que:

\begin{abstract}
Contudo, de uma forma geral, para a adequação dessa complexa ponderação que envolve três centros de interesses, creio que a melhor solução de compromisso entre a ordem econômica, a tutela dos consumidores e a proteção das próprias celebridades, demanda um ônus de informar qualificado a quem contrata a celebridade; um "dever de se informar" por parte de quem empresta a sua fama a uma publicidade respeitante às qualidades e riscos daquilo que comercializará (principalmente em produtos conexos a sua área de atuação, v.g. famoso cabelereiro ao aderir a produto de beleza) e, uma percepção mínima por parte do público do que objetivamente consiste em uma "expectativa" e o que de fato aquele produto possa lhe proporcionar e, além disso, se efetivamente vale a pena se vincular com aquele fornecedor. ${ }^{56}$
\end{abstract}

Assim sendo, a publicidade qualificada (clara, ostensiva, correta e adequada) se traduz como a melhor forma do influenciador emprestar sua fama e influência de modo benéfico a todos integrantes da relação jurídica de consumo, de modo a tornar a prevenção o âmago da temática, criando um ambiente seguro para os consumidores e atraente aos fornecedores, com a finalidade de se evitar, e mitigar ao máximo eventuais infortúnios que poderão vir a ocorrer no âmbito da publicidade digital.

\section{CONSIDERAÇÕES FINAIS}

${ }^{55}$ BRAGA NETTO, Felipe Peixoto. A dimensão preventiva da responsabilidade civil. In: BRAGA NETTO, Felipe Peixoto; SILVA, Michael César (Org.). Direito privado... p. 86.

${ }^{56}$ ROSENVALD, Nelson. O direito civil em movimento: desafios contemporâneos. 2. ed. Salvador: Juspodivm, 2018. p. 212. 
Ante às inovações publicitárias agregadas a influência digital, respeito é merecido a livre iniciativa e a função publicitária, impulsionando o mercado de consumo de modo a gerar capital, não se desestimulando ações de marketing ou criação de produtos e serviços, mas atentando-se a proteção do consumidor e a livre concorrência.

Injusto e ilógico seria coibir a atuação de tais indivíduos no ramo da publicidade digital, mas, é imprescindível a observância aos preceitos da boa-fé objetiva, informação, transparência e confiança, que devem sempre fazer-se presentes na relação consumerista.

Dessa forma, ainda se apresentariam aos fornecedores como uma atraente alternativa para alavancar a divulgação de seus produtos ou serviços, por meio da influência e conexão que tais indivíduos possuem no âmbito digital, e o consumidor estaria seguro quanto às informações dadas pelos influenciadores que acompanham virtualmente. Para que a confiança e a transparência se traduzam como padrões de comportamento a serem seguidos neste meio, exigirá esforço, mas alguns influenciadores digitais já caminham neste sentido, tornando possível aliar sua influência na plataforma digital com a publicidade lícita, de maneira que todos possam se beneficiar e serem respeitados na relação de consumo virtual.

$\mathrm{Na}$ ocorrência de danos, possuem papel importante os consumidores, que diante a tais ilícitos civis, devem alertar os órgãos de regulamentação (como por exemplo o Conar), para fins de se corrigir e coibir tais ilícitos, de modo a tornar-se padrão de conduta a observância dos preceitos norteadores da boa-fé objetiva e seus princípios correlatos nas plataformas digitais. Logo, o ordenamento pátrio deverá se aliar as funções precaucionais da responsabilidade civil, visando ao equilíbrio das relações jurídicas de consumo, em especial na fase pré-contratual, em que o consumidor se encontra em posição de patente vulnerabilidade, e em especial, pela presença da assimetria de informações na relação de consumo virtual, por possuir pouco ou nenhum conhecimento acerca do produto ou serviço veiculado em si, ficando a mercê das informações e atrativos propagados pelos influenciadores digitais e fornecedores.

Portanto, nessa linha de raciocínio, será possível atingir-se um patamar em que possa a publicidade ser agregada no âmbito digital de forma benéfica a todos polos da relação jurídica de consumo, de forma que, as novas tecnologias e meios de comunicação possam proporcionar um ambiente adequado e seguro aos fornecedores e consumidores, respeitando-se a vontade e as pretensões de ambos, na divulgação de publicidade nas redes sociais, para fins de se promover a eficiente circulação de bens/serviços, com esteio na necessária observância dos preceitos da boa-fé objetiva, informação, transparência e confiança no mercado de consumo. 


\section{Revista IBERC}

v. 2, n. 2, p. 01-21, mai.-ago./2019

www.responsabilidadecivil.org

\section{REFERÊNCIAS}

ALMEIDA, Marcos Inácio Severo de. et al. Quem Lidera sua Opinião? Influência dos Formadores de Opinião Digitais no Engajamento. Revista de Administração Contemporânea. Rio de Janeiro: ANPAD, 2018, v. 22, n. 1, p. 115-137.

BECK, Ulrich. Sociedade de Risco: rumo a uma outra modernidade. São Paulo: Editora 34, 2010.

BENJAMIN, Antônio Herman V.; MARQUES, Cláudia Lima; BESSA, Leonardo Roscoe. Manual de direito do consumidor. 7. ed. São Paulo: Revista dos Tribunais, 2016.

BEZERRA, Glícia Maria Pontes. Publicidade e defesa do consumidor no Brasil: histórico, cenário político e disputas sobre a implementação do Código em contraponto à autorregulamentação publicitária no país. Revista de Direito do Consumidor. São Paulo: Revista dos Tribunais, 2017, v. 26, n. 111 , p. $197-218$.

BRAGA NETTO, Felipe Peixoto. A dimensão preventiva da responsabilidade civil. In: BRAGA NETTO, Felipe Peixoto; SILVA, Michael César (Org.). Direito privado e contemporaneidade: desafios e perspectivas do direito privado no século XXI. Belo Horizonte: D'Plácido, 2014, p. 75-91.

BRAGA NETTO, Felipe Peixoto. Manual de direito do consumidor: à luz da jurisprudência do STJ. 11. ed. Salvador: Juspodivm, 2016.

BRASIL. Lei $n^{\circ}$. 8.078, de 11 de setembro de 1990. Código de Defesa do Consumidor. Disponível em: http://www.planalto.gov.br/ccivil_03/LEIS/L8078.htm. Acesso em: 21 jul. 2018.

BRASIL. Lei $\mathrm{n}^{\circ}$. 10.406, de 10 de janeiro de 2002. Código Civil. Disponível em: http://www.planalto.gov.br/ccivil_03/LEIS/2002/L10406.htm. Acesso em: 21 jul. 2018.

BRASIL. Constituição da República Federativa do Brasil. Disponível em: http://www.planalto.gov.br. Acesso em: 29 jul. 2018.

CATALAN, Marcos. A morte da culpa na responsabilidade contratual. São Paulo: Revista dos Tribunais, 2013.

CONAR. Código Brasileiro de Autorregulamentação Publicitária Código e Anexos. Disponível em: http://www.conar.org.br/. Acesso em: 29 jul. 2018.

CONAR (Conselho Nacional de Autorregulamentação Publicitária). Representação $n^{\circ}$ 211/15. Julg. Fev. 2016. Disponível em: http://www.conar.org.br/processos/detcaso.php?id=4259. Acesso em: 26 jul. 2018.

DEL MASTRO, André Menezes. A função punitivo-preventiva da responsabilidade civil. Revista da Faculdade de Direito, Universidade de São Paulo, 2016, p.765-817.

DIAS, Lucia Ancona Lopez de Magalhães. Publicidade e direito. São Paulo: Revista dos Tribunais, 2010.

FACHIN, Luiz Edson. Da Felicidade Paradoxal à Sociedade de Riscos: Reflexões sobre Risco e Hiperconsumo. In: LOPEZ, Teresa Ancona; LEMOS, Patrícia Faga Iglecias; RODRIGUES JUNIOR, Otavio Luiz (Coordenadores). Sociedade de risco e Direito privado: desafios normativos, consumeristas e ambientais. São Paulo: Atlas, 2013, p. 380-393. 


\section{Revista IBERC}

v. 2, n. 2, p. 01-21, mai.-ago./2019

www.responsabilidadecivil.org

FARIAS, Cristiano Chaves de; BRAGA NETTO, Felipe Peixoto; ROSENVALD, Nelson. Novo tratado de responsabilidade civil. São Paulo: Atlas, 2015.

FRANCO, Denise Sirimarco. A publicidade no Instagram feita por digital influencers à luz da boa-fé objetiva e do dever de informação. 2016. Dissertação Curso de Pós-Graduação Lato Sensu da Escola de Magistratura do Estado do Rio de Janeiro, Rio de Janeiro. p. 10. Disponível em: http://www.emeri.tjri.jus.br/paginas/trabalhos_conclusao/2semestre2016/pdf/DeniseSirimarcoFranco.p df. Acesso em: 26 jul. 2018.

FREIRE, Paula Vaz. Sociedade de Risco e Direito do Consumidor. In: LOPEZ, Teresa Ancona; LEMOS, Patrícia Faga Iglecias; RODRIGUES JUNIOR, Otavio Luiz (Coordenadores). Sociedade de risco e Direito privado: desafios normativos, consumeristas e ambientais. São Paulo: Atlas, 2013, p. 375-379.

GOMES, Marcelo Kokke. Responsabilidade Civil: dano e defesa do consumidor. Belo Horizonte: Del Rey, 2001.

GUIMARÃES, Paulo Jorge Scartezzini. A publicidade ilícita e a responsabilidade civil das celebridades que dela participam. 2. ed. rev., atual, e ampl. São Paulo: Revista dos Tribunais, 2007.

GUSTIN, Miracy Barbosa de Sousa; DIAS, Maria Tereza Fonseca. (Re)pensando a pesquisa jurídica: teoria e prática. 3. ed. Belo Horizonte: Del Rey, 2010.

KARHAWI, Issaaf. Influenciadores digitais: o Eu como mercadoria. In: SAAD, Elizabeth Corrêa; SILVEIRA, Stefanie Carlan. (Orgs.). Tendências em comunicação digital. São Paulo: ECA/USP, 2016.

KERSCHENSTEINER, Klaus. UNBOXING: RELEVANT TO MEDIA LINGUISTICS? Disponível em: http://10plus1journal.com/wpcontent/uploads/2015/09/06_MIN_TALK_Kerschensteiner1.pdf. Acesso em: 29 jul. 2018.

KING, Stephen. Escuridão total sem estrelas. Tradução de Viviane Diniz. Rio de Janeiro: Objetiva, 2015.

LISBOA, Roberto Senise. Confiança contratual. São Paulo: Atlas, 2012.

LIPOVETSKY, Gilles. A felicidade paradoxal: ensaio sobre a sociedade do hiperconsumo. São Paulo: Companhia das Letras, 2007.

LOPEZ, Teresa Ancona. Princípio da precaução e evolução da responsabilidade civil. São Paulo: Quartier Latin, 2010.

LOPEZ, Teresa Ancona. Responsabilidade Civil na Sociedade de Risco. In: LOPEZ, Teresa Ancona; LEMOS, Patrícia Faga Iglecias; RODRIGUES JUNIOR, Otavio Luiz (Coordenadores). Sociedade de risco e Direito privado: desafios normativos, consumeristas e ambientais. São Paulo: Atlas, 2013, p. 3-13.

MARQUES, Claudia Lima. Contratos no código de defesa do consumidor: o novo regime das relações contratuais. 7. ed. São Paulo: Revista dos Tribunais, 2014.

MORAES, Maria Celina Bodin de. Danos à pessoa humana: uma leitura civil-constitucional dos danos morais. 2.ed. Rio de Janeiro: Editora Processo, 2017.

OXFORD. English Living Dictionaries. Disponível em: https://en.oxforddictionaries.com/definition/feed.

Revista IBERC, Minas Gerais, v. 2, n. 2, p. 01-21, mai.-ago./2019 


\section{Revista IBERC}

v. 2, n. 2, p. 01-21, mai.-ago./2019

www.responsabilidadecivil.org

Acesso em: 17 out. 2018.

RAIS, Diogo; BARBOSA, Nathalia Sartarello. O reflexo da sociedade do hiperconsumo no instagram e a responsabilidade civil dos influenciadores. Revista Direitos Culturais, n.30, 2018, p.73-88.

ROSENVALD, Nelson. As funções da responsabilidade civil: a reparação e a pena civil. 2. ed. São Paulo: Atlas, 2014.

ROSENVALD, Nelson. O direito civil em movimento: desafios contemporâneos. 2. ed. Salvador: Juspodivm, 2018.

SCHREIBER, Anderson. Novos paradigmas da responsabilidade civil: da erosão dos filtros da reparação à diluição dos danos. 6. ed. São Paulo: Atlas, 2015.

SILVA, Michael César. Convergências e assimetrias do princípio da boa-fé objetiva no Direito Contratual contemporâneo. In: BRAGA NETTO, Felipe Peixoto; SILVA, Michael César (Org.). Direito privado e contemporaneidade: desafios e perspectivas do direito privado no século XXI. Belo Horizonte: D'Plácido, 2018, v.2, p. 99-141.

SIMAS, Danielle Costa de Souza; SOUZA JÚNIOR, Albefredo Melo de. Sociedade em rede: os influencers digitais e a publicidade oculta nas redes sociais. Revista de Direito, Governança e Novas Tecnologias. Salvador, 2018.

SIQUEIRA, Dirceu Pereira; NUNES, Danilo Henrique. Conflitos digitais: cidadania e responsabilidade civil no âmbito das lides cibernéticas. Revista Jurídica da UNI7. Centro Universitário 7 de Setembro, Fortaleza, v. 15, n.2, p. 127-138, jul.-dez., 2018.

WITKER, Jorge. Como elaborar una tesis en derecho: pautas metodológicas y técnicas para el estudiante o investigador del derecho. Madrid: Civitas, 1985.

Recebido: 02.01.2019

Aprovado: 10.02.2019

Como citar: BARBOSA, Caio César do Nascimento; SILVA, Michael César; BRITO, Priscila Ladeira Alves de. Publicidade ilícita e influenciadores digitais: novas tendências da responsabilidade civil. Revista IBERC, Minas Gerais, v. 2, n. 2, p. 1-21, mai.-ago./2019. 